\title{
"Investigating the Effectiveness of Vocabulary Learning Strategies among Physical Therapy Students at Delta University."
}

By

Abdelrahman Elsayed AlAdl

English Lecturer

Delta University for Science and Technology

\begin{abstract}
This study aimed at investigating six assigned strategies to improve vocabulary acquisition. The objective is to determine the most frequency used and most preferred ones among the students of Physical Therapy at Delta University. The subject was sixty level one students that contributed in this study. The tool of this study was a modified version of questionnaire that is based on Seddigh and Shokrpur, (2012); Gu \& Johnson, (1996), and Oxford, (1990). It consisted of 30 items were set to evaluate the students' tendency towards vocabulary acquisition. The data were analyzed using SPSS 17 and ANOVA. The findings showed that using Arabic dictionary and word formation were the most repeatedly used strategies among students followed by word collocation, synonyms, autonomy and Semantic mapping. The study discusses the assigned vocabulary learning strategies in the medical classroom, from students' perspective, which could deeply guide English language students in their establishing of language acquisition and could assist instructors and curricula designers to improve proper educational contexts.
\end{abstract}

Key words: Vocabulary learning strategies, Word collocation, Semantic mapping, bilingual dictionaries, Medical sciences students.

\section{Introduction}

Researchers realize the vital role of vocabulary in studying foreign language learning. However, students always reveal their difficulty in acquiring and remember more vocabulary. Providing useful vocabulary acquisition approaches is therefore more useful than giving students a huge sum of new terms. Medical science students, particularly physical therapist, should employ efficient learning approaches and methods to enhance their vocabulary acquisition.

Vocabulary learning strategies (VLS) are procedures followed by students to enhance their own learning. Moreover, Schmitt (1997) stated that VLS are any efforts performed by the learners which affected on their vocabulary acquisition. In addition, Cameron (2001) reported that VLS are procedures followed by the learners to guide themselves in recognizing and acquiring vocabulary. They are essential for students to 
monitor their own studying process. They also guide them in dealing with each new term they face in a good manner.

By equipping with strategies of vocabulary learning, students gradually become proficient in learning verbal communication, because they develop their autonomy by facilitating self-directed process, and guiding them to organize their learning (Oxford, 1990). Benson (2001), considered the teaching strategy as an approach to make students involved in and regulate their personal studying. Since the late 1970s VLS attracted much consideration of the researchers, regarding the practical role of them in the process of vocabulary acquisition.

The current study assigned six vocabulary learning strategies among physical therapy students to investigate the most effective and preferred strategy among medical college students. The assigned VLS were chosen in the light of medical terms acquisition and other communication purposes. Medical college students have to practice different tasks while dealing with new vocabulary. In a research by Richards (1976), there is a list of different tasks about a word students should acquire. The elements of these tasks included the following word structures; 1. The grammatical manner 2. The word structure prefix, suffix, and "root") 3. The meaning(s) of the word, 4. The verbal and printed forms, 5. The word collocations, 6. What relatives it has (similar or opposite in meaning), 7. What associations it has, 8. Its frequency. So, this study assigned some VLS that might cover the previous items. They are as follow;

\section{Teaching Word Collocation Strategy}

The term collocation is the method in which two or more words are usually combined, such as; heavy rain. Collocations appear as: [1] Verb + Noun (lift a blockade, break a code) [2] Noun + Verb (clock ticks, water freezes) [3] Adverb + Adjective (closely related, deeply absorbed) [4] Verb + Adverb (appreciate sincerely, affect deeply) [5] Adjective + Noun (best wishes, strong tea).

Collocations are considered parts of knowledge that are important for EFL and ESP students to communicate or write proficiently. McCarthy (1988) reported that Collocations can meet students' predications about what types of words go with other ones. So they may not go about rebuilding the language each time they need to pronounce something.

2. Word Formation Strategy

Word formation defined by Carter, (2000) as production and recognition (writing and communication) of word formation processes. The following table is an example of word formation process. 


\section{Abdelrahman E. AlAdl}

\section{Table (1) A Chart of word Formation}

\begin{tabular}{|c|l|l|l|}
\hline Verb & Noun & Adjective & adverbs \\
\hline -E, ATE, EY & ION, - TION & IV, -ED & LY \\
\hline Affect & Effect & Effective & effectively \\
\hline Activate & Activation & Activated & \\
\hline Respond & Responsibility & Responsible & \\
\hline Infect & Infection & Infected & \\
\hline
\end{tabular}

\section{Synonyms Strategy}

It is commonly known as a phrase or a word that means nearly or closely the same as another phrase or word in the same language. It can be performed to help the student recognize the various aspects of meaning. Synonyms facilitate to enhance a student's acquisition of words and give substitute phrases or words immediately. Synonyms can also be valuable for students, to construct several phrases and words that they already know.

Synonyms exercises are useful for the students; teacher should encourage them to provide more and more words for the same word meaning and not to depend only on their equivalent Arabic meaning.

\section{Antonyms Strategy}

It is the process of word contradictions or opposites. Getting the opposites of words is an important process for students to master their usage of language in different skills. There are various activities that help students use this strategy. For example, they might be requested to compose several alternatives of opposites of given words (heat/cold, hard/soft, flexible/rigid).

5. Strategy of Semantic mapping

It is employed to stimulate and engage students in reading, writing and thinking. It reinforces words acquisition improvement by guiding students uniting new words and information with prior knowledge. This strategy may performed by building sets of words into an image, which has a key model at the midpoint and related words and concepts linked with the key concept. Adopting this strategy to acquire new vocabulary supplies a structure for classifying conceptual information in the method of defining a word. A graphic organizer or a distinctive puts the word at the midpoint and includes concepts or additional links linked with the essential word. (Liu, 2016).

6. Using bilingual dictionaries

It is a basic strategy in acquiring new vocabulary. Instructors should enforce students to look for words in specific dictionaries. 
Gonzalez (1999) reported that dictionary searching process was difficult but indispensable, and that college students require the ability to be practical users of dictionaries. Survey dictionaries accessing can be one valuable and efficient process of recognizing a word intensely.

\section{Importance of the Study}

It is crucial for ESP medical students to acquire and study complex medical terms. This affects on their advancement in the study of medical contents and in their work life at all. Investigating the strategies of Vocabulary acquisition for medical students can guide teachers to be more thoughtful of what approaches that are utilized by students and their role in enhancing vocabulary acquisition. It can also guide curricula designers to meet students' learning styles and habits in learning new vocabulary. Furthermore, getting a concept of VSL that are used by students will enhance knowledge of classroom instruction and curricula arrangements regarding vocabulary learning acquisition. It also guides the students to improve approaches to become more self-directed learners.

\section{Literature Review}

Many researchers presented Various VLS classification systems, for example, Schmitt (2000) showed two methods of them: consolidation and discovery strategies. The first were performed to secure meanings when the students encounter the words again while the second are employed to get the meaning of new words when the students face them for the first time.

Moreover, Gu and Johnson (1996) reported that many of their skillful students performed dictionary strategies and predicating than any other approaches. Arani (2005) also accomplished a study to investigate the strategies of vocabulary acquisition among medical students. The results revealed that written repetition strategy was frequently used by the students, followed by; spoken repetition, and bilingual dictionary. The study also revealed that high proficient students utilize strategies more than low ones.

Xia, (2007) identified the commonly used VLS of Taiwanese college students. It was revealed that the frequent preferred approaches were strategies of memorization while the least common performed strategies were those connected to activities of social learning, study aids and the bilingual dictionaries usage.

In addition, the study of Kafipour and Sarani (2008) revealed that using VLS improves the performance of students in studying the skills of foreign language.

Kaivanpanah and Alavi (2008) investigated the effects of students' abilities on assessing their own recognizing complex words, and their 


\section{Abdelrahman E. AlAdl}

efficiency. It was revealed that efficiency in the second language and gender affect students' self-evaluation. The findings showed that students do not have a precise evaluation of their recognition regarding the meaning of difficult words in passages. It was indicated that the proficiency of students' predicting is connected to their range of accuracy and gender.

The study by Soodmand Afshar (2010) examined the frequently used VLS by EFL majors and the effects of gender factor on the overall strategy usage. The participants were divided into good and poor students based on their academic scores of a placement test. The findings showed that all students commonly used frequent approaches most or least commonly but the position of the strategies sometimes changed in the tables. There was no considerable variation in the mean frequency of the overall strategy use of male and female participants.

Seddigh and Shokrpour (2012) examined a sample of medical students and showed that the most commonly utilized VLS were dictionary strategies and guessing while the least used strategies were study preference and social strategies.

Palmer, Boon, and Spencer (2014) made a comparison between student-constructed concept-mapping models with dictionaries usage in the process of vocabulary acquisition among four seventh-graders. Regarding the method of dictionary usage, each student searched for certain words in the bilingual dictionary, and then wrote down the word in a sentence on written papers. In the concept-mapping model, the students submitted a concept map that shows the definition of a word, and then wrote the word in a sentence. Findings indicated considerable developments among the majority of students in their vocabulary acquisition connected with the usage of concept-mapping model comparing with the strategy of dictionary.

The aim of Kabouha's study (2015) was to find out the frequent employed VLS by medical students. The findings showed that the frequent utilized strategies of vocabulary acquisition were bilingual dictionary strategies and guessing strategies. The least utilized strategies were written notes and selective attention.

\section{Statement of the problem}

Research on students' preference has suggested that they influence students' learning strategies. More research is needed to study the evolution of learning preference and strategies to better understand the conditions that lead to students' development. Thus, the current study aimed at investigating the variations in students' vocabulary acquisition preference and approaches during the first semester of learning medical terms in English. In summary, determining the used VSL of physical 
therapy students to shed light on their personal variations in vocabulary acquisition, thereby making ESP instructors and curricula designers more conscious of their roles in setting suitable contents and activities to guide students in improving their vocabulary acquisition. Moreover, identifying VSL of these students could enhance their understanding of classroom instruction and curricula development concerning vocabulary acquisition.

\section{Research Questions}

1- What are the most frequently employed Strategies of Vocabulary Learning acquisition by Physical Therapy students at Delta University?

2- What is the students' perception of employing strategies to guide them in the acquisition of the new medical terms?

\section{Methodology}

\section{A. Participants}

The participants in this study were 60 freshmen Physical Therapy students at Delta University for Sciences and Technology. The study was conducted in the second semester of first preparatory year during 2016/ 2017 academic year. The treatment was conducted on "English Two and Medical Terminology" academic course.

\section{B. Instrument}

The study employed a questionnaire (Appendix A), which was prepared relying on other researchers (Oxford, 1990; Gu \& Johnson, 1996 and Seddigh \& Shokrpur, 2012). It was composed of 30 items that are connected to the students' strategies of vocabulary learning. The specific items were categorized onto six segments as bilingual dictionary strategy, Word formation strategy, word collocation strategy, synonyms strategy, antonyms strategy and semantic mapping strategy. The students were requested to response to each item using 5-point Likert scale: 'never', 'rarely', 'sometimes', 'often' and 'always'.

\section{Procedures}

The questionnaire was administered by the end of semester; therefore students have practiced enough on the assigned strategies through their English course. The students were requested to mark each mentioned strategy regarding their frequent usage.

\section{Data Analysis}

The given data were analyzed by performing SPSS software. The Descriptive statistics were employed to explore the used strategies of vocabulary acquisition by students. The frequencies of the responses were calculated in percentages. Also, the means and standard deviations were determined for the six strategies listed in the questionnaire. ANOVA was conducted to show the extents of variations among the mean percentage scores of the six strategies. 


\section{Abdelrahman E. AlAdl}

\section{Results}

Analysis of the data revealed that students were familiar with using all the vocabulary learning strategies that have been assigned. These strategies have been used by the participants along the semester course. To determine the degree of VLS usage among physical therapy students at Delta University and answer the first study question, descriptive statistics were used to find out the standard deviations and mean percentage scores of the six types and their sections (30 items). Table1 shows Descriptive Statistics for the Strategies Usage Frequency.

Table (2) Students' Usage of VLS: Descriptive statistics

\begin{tabular}{|c|c|c|c|c|c|}
\hline Strategy & No & Min & Max & Mean & S.D. \\
\hline $\begin{array}{c}\text { Arabic } \\
\text { dictionary }\end{array}$ & 60 & 21.00 & 99 & 68.81 & 19.25 \\
\hline Word formation & 60 & 36.12 & 92.23 & 67.23 & 11.62 \\
\hline $\begin{array}{c}\text { Word } \\
\text { collocation }\end{array}$ & 60 & 31.34 & 88.71 & 63.11 & 10.85 \\
\hline Synonyms & 60 & 19.00 & 95.55 & 62.15 & 14.16 \\
\hline Antonyms & 60 & 18.00 & 100 & 61 & 17.12 \\
\hline $\begin{array}{c}\text { Semantic } \\
\text { mapping }\end{array}$ & 60 & 20.01 & 99 & 58.43 & 18.45 \\
\hline Total & 60 & 43.45 & 82.45 & 82.45 & 8.83 \\
\hline
\end{tabular}

Table 2 showed that, using bilingual dictionary and Word formation strategies were the most frequently employed strategies among students followed by Word collocation, Synonyms, autonomy and Semantic mapping. Semantic mapping was appeared as the least frequently performed strategy. One way analysis of variance showed that there was a statistically significant difference $(\mathrm{p}<0.001)$ among the mean percentage of the six strategies.

Moreover, bilingual Dictionary strategies were the frequent used strategies among students with a mean percentage score of 68.81 . The reason for this is that they faced new words and medical terms in their studying. The students employed the bilingual dictionary strategy more than monolingual dictionaries. They haven't the sufficient skills to utilize that type of dictionaries appropriately. These findings revealed that they should be encouraged to depend less on Arabic and more on English to memorize the English equivalents or write down their meanings.

According to the second question that is related to the students' perspective towards the usefulness of the assigned strategies table 2 shows its Descriptive Statistics. 
"Investigating the Effectiveness of Vocabulary Learning Strategies among Physical Therapy Students at Delta University."

Table (3) Descriptive Statistics for usefulness of Strategies

\begin{tabular}{|c|c|c|c|c|c|c|}
\hline Strategy & No & Mean & Useful found \% & S.D. & Min. & Max. \\
\hline Arabic dictionary & 60 & 2.3100 & 78.37 & .48712 & 2.02 & 3.05 \\
\hline Word formation & 60 & 2.2300 & 74.1 & .55377 & 2.00 & 3.00 \\
\hline Word collocation & 60 & 2.2900 & 68.3 & .49329 & 1.00 & 3.00 \\
\hline Synonyms & 60 & 2.1300 & 64.23 & .53852 & 2.00 & 3.00 \\
\hline Antonyms & 60 & 2.1700 & 63.2 & .57155 & 2.00 & 3.00 \\
\hline Semantic mapping & 60 & 2.0800 & 58.7 & .45461 & 1.00 & 3.00 \\
\hline
\end{tabular}

Table 3 shows the results of the analysis of students' perspective towards the usefulness of the employed strategies. It indicated that the mainly valuable strategy was "using bilingual English dictionary" at mean percentage of $78.37 \%$ followed by "Word formation" at $74.1 \%$, and Word collocation. Two other strategies that have been found to be near similarly useful is "Synonyms" and "Antonyms" at $64.23 \%, 63.2$. The least useful strategy for them is "Semantic mapping" at $58.7 \%$.

\section{Discussion}

The findings of the current study showed that the most employed strategies by physical therapy students at Delta University were bilingual dictionary and word formation, while the least one was semantic mapping. The results revealed a significant variation among the mean scores of the six strategies. This is agreed with the results of Seddigh\& Shokrpur (2012) and Kabouha (2014) that were conducted among medical students. Regarding dictionary strategy, most students depend on bilingual dictionary because they face new medical terms for the first time. They have not enough experience or time in their first year to use more strategies yet. Then, they had to use another strategy related to the nature of medical terms, which are often formed of prefixes, root and suffixes. So the next preferred strategy for them is word formation, which helped them to deal with new medical terms. The least used strategy was semantic mapping. It was difficult for students to identify_relationship between their prior knowledge and new one to get the meaning of given vocabulary.

\section{Conclusion}

The findings of the current study are agreed with previous researches which recommended that the highest employed strategies were guessing and using Dictionary (Seddigh \& Shokrpur, 2012). The results also revealed that the students' preference is to study individually to acquire new vocabulary. The results also recommended that if the students were more conscious of the varied strategies and their different 


\section{Abdelrahman E. AlAdl}

employment, the students would be more proficient in performing them, in addition, becoming more efficient in acquiring new medical terms. Thus, when teaching medical terms, instructors could conduct different strategies and lead them to employ these strategies in their educational tasks. In this line, additional research may be carried out regarding how to perform these strategies in classroom instruction and how to train them to apply Vocabulary Learning Strategies effectively.

\section{Implications and Recommendations}

Regarding the aim of this study, it is recommended that the ESP Lecturers should help students be become familiar with the significance of VLS in improving their English language. More training should take place with regard to the relevant strategies for acquiring medical vocabulary. The lack of monolingual dictionary usage among students might come out from deficient acquaintance of using them. The lecturers should encourage them to utilize the monolingual dictionary properly, consequently, emphasis is laid on using them more than Arabic dictionary in finding out meaning of English terms or writing down their meanings. At last, by teaching medical vocabulary, teachers could instruct several strategies and guide students to apply them in their learning practices. Students should also attempt to practice these strategies appropriately. Moreover, additional studies can be conducted regarding how to employ these strategies in classroom instruction and learning and how to guide students to perform Vocabulary Learning Strategies effectively. Therefore, in light of the study findings, the researcher suggests that the instructors should raise the awareness of students, realize the relevant strategy for every condition, recommend a variety of strategies and let them make a decision which ones are more effective for them. 


\section{Reference}

1. Arani, J., A. (2005). Learning strategies of English medical terminologies in the students of medicine. Kashan University of Medical Sciences.

2. Benson, P. (2001). Teaching and researching: Autonomy in language learning. London: Longman.

3. Cameron, L. (2001). Teaching languages to young learners. Cambridge: Cambridge University.

4. Carter, R. (2000), Vocabulary, Rutledge, London.

5. Denton, C. Bryan, D. Wexler, J., Reed, D. \& Vaughn, S. (2007) Effective Instruction for Middle School Students with Reading Difficulties: The Reading Teacher's Sourcebook. University of Texas.

6. Gonzalez, O., \& Gonzales, O. (1999). Building vocabulary: Dictionary consultation and the ESL student. Journal of Adolescent \& Adult Literacy, 43, 264270.

7. Gu, Y., \& Johnson, R. K. . (1996). Vocabulary learning strategies and language learning out- comes. Language Learning, 46(4), 643-679.

8. Kabouha R. H.(2014), Vocabulary Learning Strategies of Medical English Terminologies: The Case of Foundation Year Students at Ibn Sina Medical College, English for Specific Purposes World, ISSN 1682-3257, www.espworld.info, 44-15.

9. Kafipour, R., \& Sarani, A. (2008). The relationship between extroversion introversion/ tendencies of Iranian BA students of English and their English oral production. ELT profession: Challenges and prospects. Lincom $\mathrm{GmbH}$ : Muenchen.

10. Kaivanpanah, Sh., \& Alavi, S.M. (2008). Deriving unknown word meaning from context. RELC Journal, 39(1), 77-95

11. Liu, P. L. (2016). Mobile English vocabulary learning based on concept-mapping strategy. Language Learning \& Technology, 20(1), 128-140. Retrieved from http://lit.msu.edu/issues/october2016/liu.pdf

12. McCarthy, M. (1988), Vocabulary, Oxford University Press, Oxford.

13. Oxford, R. (1990). Language learning strategies: What every teacher should know. Boston: Heinle \& Heinle.

14. Palmer, J., Boon, R. T., \& Spencer, V. G. (2014). Effects of concept mapping instruction on the vocabulary acquisition skills of seventh-graders with mild disabilities: A replication study. Reading \& Writing Quarterly, 30(2), 165-182.

15. Richards, JC. (1976). The role of vocabulary teaching. TESOL Quarterly, 10,1, 7789.

16. Schmitt, N. (1997). Vocabulary learning strategies. In Norbert Schmitt \& Michael McCarthy (Eds.), Vocabulary: Description, acquisition, and pedagogy, 199-227. Cambridge: Cambridge University Press.

17. Schmitt, N. (2000). Vocabulary in language teaching. Cambridge: Cambridge university press.

18. Seddigh F.\& \& Shokrpur,N. (2012), Vocabulary Learning Strategies of Medical Students at Shiraz University of Medical Sciences, English Language Teaching, 5(2) $160-173$ _www.ccsenet.org/elt 


\section{Abdelrahman E. AlAdl}

19. Soodmand Afshar, H. (2010). Iranian EFL learners' most and least frequently used vocabulary learning strategies: the relationship to success and gender. The Iranian EFL Journal, 6(1), 72-100.

20. Xia, L. H. (2007). Strategies of English vocabulary learning. Hospital department of foreign languages institute, Jiujiang University. 


\section{Appendices}

\section{Appendix (A)}

\section{Questionnaire for Vocabulary Learning Strategies}

Name: Age:

Level of Study:

Knowing English for me is: Very Important/Important/Not so

Important/Unimportant

My proficiency in English is: Very poor/Poor/Not Bad/Good/Very

Good/Excellent

\begin{tabular}{|c|c|c|c|c|c|c|c|c|c|}
\hline No & STRATEGY & $\mathbf{N}$ & $\mathbf{R}$ & $\mathrm{s}$ & $\mathbf{o}$ & A & $\mathrm{Vu}$ & $\mathrm{U}$ & $\mathrm{NU}$ \\
\hline \multicolumn{10}{|c|}{ Dictionary Strategy } \\
\hline 1 & I use an English- English dictionary. & & & & & & & & \\
\hline 2 & I use an Arabic/English or English/Arabic dictionary & & & & & & & & \\
\hline 3 & $\begin{array}{l}\text { I look up a word in the dictionary if it is of personal } \\
\text { interest to me. }\end{array}$ & & & & & & & & \\
\hline 4 & $\begin{array}{l}\text { If there are new words in reading passage that I do } \\
\text { not know, I look them up in the dictionary. }\end{array}$ & & & & & & & & \\
\hline 5 & $\begin{array}{l}\text { I look at examples of how a word is used when I look } \\
\text { it up in the dictionary. }\end{array}$ & & & & & & & & \\
\hline \multicolumn{10}{|c|}{ Word Formation } \\
\hline 6 & $\begin{array}{l}\text { When I look up a word in the dictionary, I look to see } \\
\text { if it is a noun, a verb, an adverb, }\end{array}$ & & & & & & & & \\
\hline 7 & $\begin{array}{l}\text { To help me remember words. I pay attention to the } \\
\text { word's prefixes, roots, and suffixes ( pre-re, tion,- } \\
\text { sion, etc,). }\end{array}$ & & & & & & & & \\
\hline 8 & $\begin{array}{l}\text { I remember words by grouping them together } \\
\text { according to subject. }\end{array}$ & & & & & & & & \\
\hline 9 & $\begin{array}{l}\text { I look up all information about words such as word } \\
\text { status (singular or plural) or word type (noun, } \\
\text { pronoun..etc). }\end{array}$ & & & & & & & & \\
\hline $\mathbf{1 0}$ & I remember words by their different forms. & & & & & & & & \\
\hline \multicolumn{10}{|c|}{ Word Collocation } \\
\hline 11 & $\begin{array}{l}\text { I am aware of collocations, and try } \\
\text { to recognize them when I see them }\end{array}$ & & & & & & & & \\
\hline 12 & I remember words together that sound similar. & & & & & & & & \\
\hline 13 & $\begin{array}{l}\text { I often get the meaning of a word by knowing related } \\
\text { adj. or adv. }\end{array}$ & & & & & & & & \\
\hline 14 & $\begin{array}{l}\text { I remember words through the context in which I saw } \\
\text { them. }\end{array}$ & & & & & & & & \\
\hline 15 & $\begin{array}{l}\text { It is easier for our brains to remember and use } \\
\text { language in chunks or blocks rather than as single } \\
\text { words. }\end{array}$ & & & & & & & & \\
\hline \multicolumn{10}{|c|}{ Synonyms Strategy } \\
\hline 16 & $\begin{array}{l}\text { I look for the meaning of words by searching for their } \\
\text { synonyms. }\end{array}$ & & & & & & & & \\
\hline 17 & I always get extra words for a certain word. & & & & & & & & \\
\hline 18 & A Word synonym is the best strategy to enrich my & & & & & & & & \\
\hline
\end{tabular}




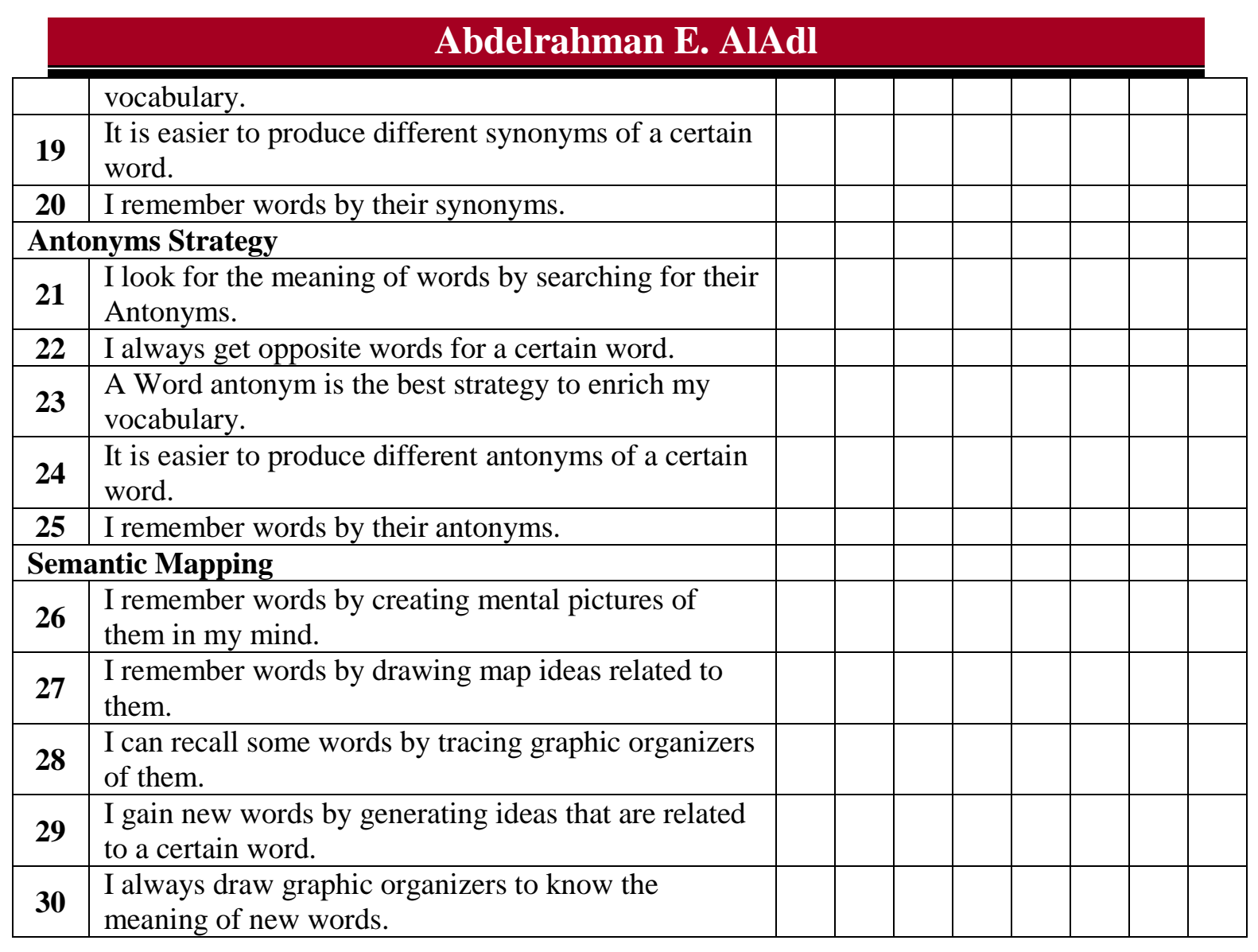




\section{Appendix (B) \\ Some used activities on Vocabulary Learning Strategies}

\section{An integrated activity on the assigned vocabulary strategies}

Adversity (ad-VÛR-si-tē) $n$. A condition or state of hardship, misfortune, trouble, difficulty, etc., is known as adversity. The word is often used in the plural (adversities) to refer to particular unfortunate events or circumstances of one's life (such as poverty, hunger, illness, accidents, etc.). Helen Keller (1880-1968), who overcame personal adversity (blindness and deafness) to become a famous author, lecturer, and humanitarian, once gave this advice to a five-year-old: "Never bend your head; always hold it high; look the world straight in the eye."

Advocate (AD-və-kāt) vb. To advocate something (a policy, an idea, a plan, etc.) is to speak or argue in favor of it, urge it, recommend it, support it, etc. American scientist Linus Pauling (who won Nobel Prizes for both chemistry and peace) is probably most famous for advocating the use of large doses of vitamin $C$ to prevent sickness and to treat the common cold. As a noun, an advocate is a person who speaks or argues in favor of some cause. Tennis champ Billie Jean King was an outspoken advocate of equality for women in professional sports.

Aesthetic (es-THET-ik) adj. The branch of philosophy concerned with the nature of beauty or art is known as aesthetics. The adjective aesthetic means "having or showing an appreciation of beauty or good taste (as distinguished from the practical or scientific)." Whereas tattoos were once applied for practical reasons (to signify one's rank, for example), today they are generally applied for purely aesthetic purposes.

Affiliation (ə-fil-ē-Ā-shən) $n$. An affiliation is a close connection or association between two or more people, groups, or organizations. Sometimes the associated elements are independent and equal, but more often one is dependent on, subordinate to, or part of the other. The verb is affiliate. Radcliffe College for women is affiliated with Harvard University (in fact, Radcliffe students are instructed by the Harvard faculty).

I. Does the definition on the right fit the word on the left? Answer yes or no.

1. Affinity: wisdom

2. Aesthetic: unconscious

3. Adverse: harmful

III. Substitute one of the following words for each of the italicized expressions in the sentences below: adulate, advocate, affirm 


\section{Abdelrahman E. AlAdl}

1. Many doctors

2. Scientists cannot

3. Teenagers often

IV. Are the two words on each line similar or opposite?

1. aegis / protection $\quad 2$. Affable / cruel

/ clumsy a low-cholesterol diet. the existence of Bigfoot. rock stars.

\section{4 \\ Collocations with -ing forms \\ A balancing act \\ This expression is used to refer to a situation that requires careful handling of opinions, views or activities. \\ An eating disorder \\ An eating disorder is a psychological or medical problem. People suffering from an eating disorder eat either too much or too little food. \\ A drinking problem \\ A person suffering from a drinking problem is an alcoholic. \\ A running mate \\ If you are trying to get elected as the president of your country, you will pick someone as your 'running mate'. In this case, if you become the president, your 'running mate' will become the vice president. \\ Growing pains \\ Used to refer to the problems that an organization experiences as it grows. \\ Asking price \\ The asking price is the price suggested by the seller. Of course, the buyer can negotiate for a lower price. \\ antriparto}

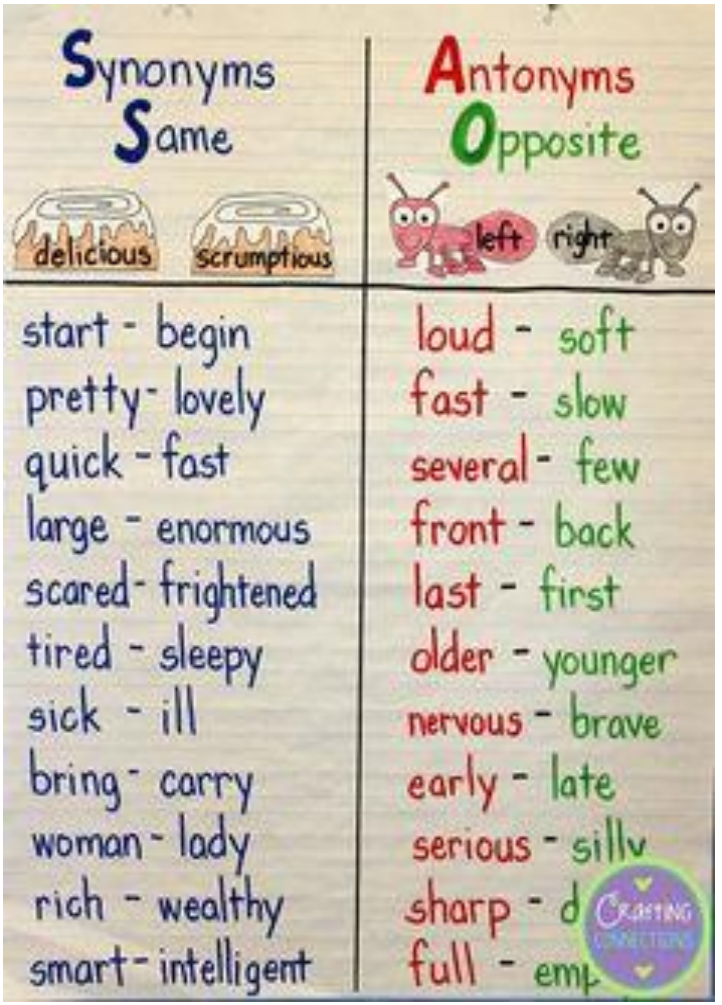

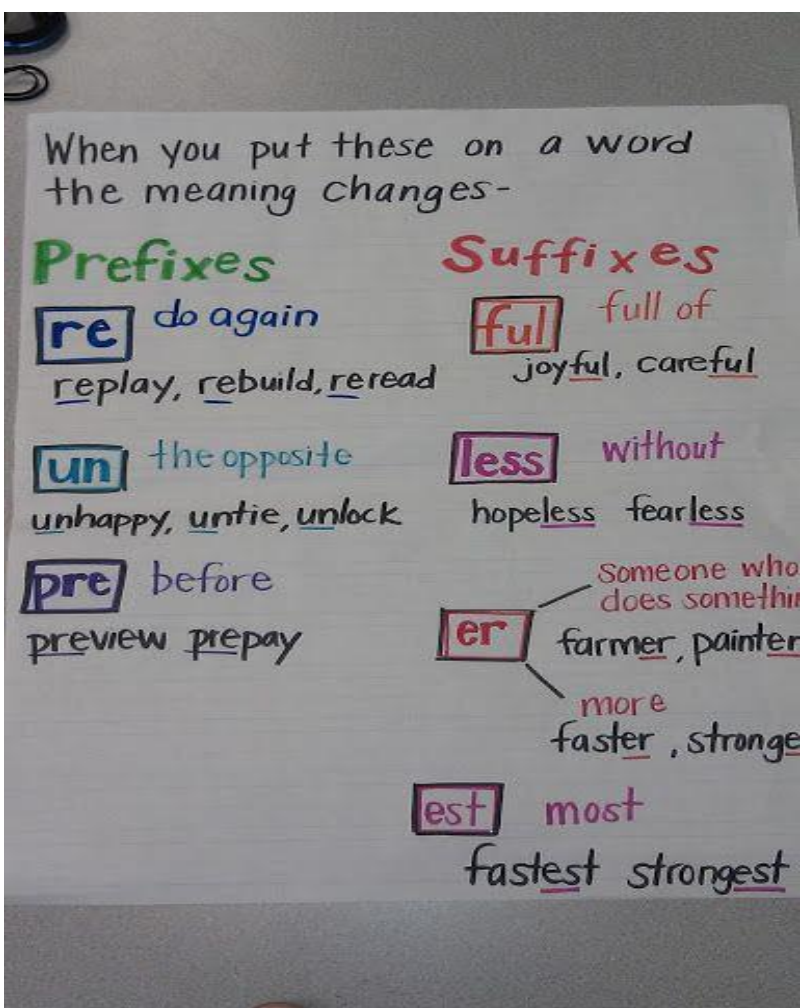




\section{Appendix (c)}

\section{A lesson plan for semantic mapping vocabulary strategy}

\section{Introduction}

\section{Vocabulary- Semantic Mapping}

Semantic mapping is a strategy for graphically representing concepts. A semantic word map allows students to conceptually explore their knowledge of a new word by mapping it with other related words or phrases similar in meaning to the new word.

There are three components to a semantic map:

1. Core question or concept: this is a key word or phrase that is the main focus of the map.

2. Strands: subordinate ideas that help explain or clarify the main concept. These can be generated by the students.

3. Supporting information: details, inferences and generalization that are related to each strand. Supports clarify the strands and distinguish one strand from another.

The following teaching steps are adapted from (Denton, 2007)

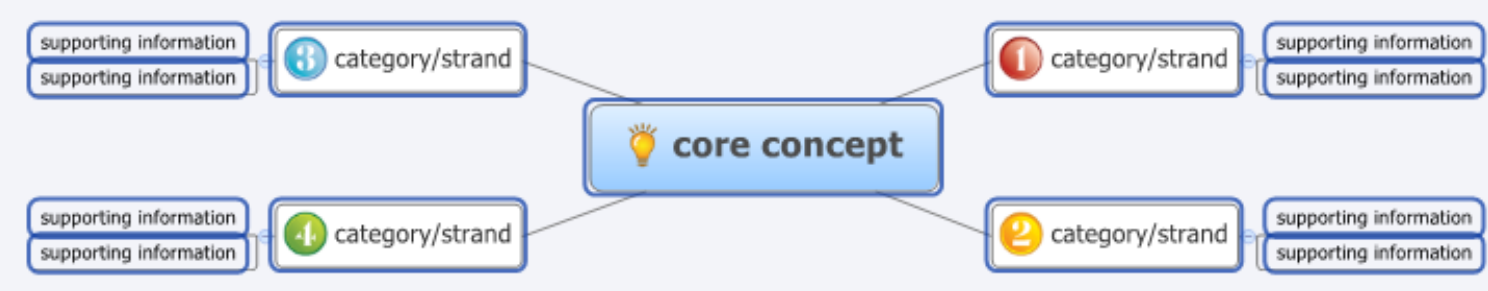

\section{Purpose}

The students will associate new word meaning with prior knowledge through the use of a semantic map.

\section{Materials}

- Topic or text

- Overhead projector, chalkboard, chart paper or Interactive White Board (IWB).

\section{Preparation}

Preview the text, looking for content words, or challenging words that students are likely to see and use often in academic settings. Prioritise the words students must know in order to understand the topic or text (See Vocabulary - Which words do I teach?). 


\section{Abdelrahman E. AlAdl}

\section{Teaching steps}

\section{State objective/purpose}

State the purpose of the lesson.

Today we are going to make a semantic map. Information is stored in your brain in categories or groups. Words in your memory are linked to other words based on their relationships. So, if you can connect a new word with a word you already know, you will be better able to remember the new word. I'm going to show you how to go through this process today by developing a semantic map.

Introduce the text/topic.

Write the topic/concept on the board (or overhead/IWB).

\section{Model and teach with the whole class}

- Ask students to brainstorm or think of words related to the topic/concept. Think pair share can be used to support brainstorming.

List all of the words on one-half of the board (or overhead). Write down all appropriate student responses.

Ask questions to lead students to identify words related the topic/concept.

$\square$ Any unfamiliar words give a brief definition for each.

- Draw a circle with the topic in the middle.

- Read through the list of brainstormed words and model using Think Aloud how to identify categories to group the words.

- Ask students to identify further with categories. Write each category or strand in a circle and connect it to the topic.

\section{Guided practice with partners}

- Assign partners and give pairs a copy of the semantic map. Ask pairs to generate any remaining category or strand titles and to categorise the brainstormed words.

- Ask students to come up with additional words for each category and any supporting information.

- Circulate around the room and be available for guidance and feedback. Check each pair of students to check for understanding. Be prepared to model again if needed.

- Ask pairs to add a blank category to their semantic map to fill in after they read the text. As you circulate around the classroom, ask leading questions to guide student responses.

- Return to the map on the board and whole-class grouping.

- Ask for student responses to each category and write appropriate responses on a master semantic map. Allow students to add words to their semantic maps based on class discussion and the master semantic map. 
- Read the selected text or have students read the text in pairs. Remind students to be aware of target words in the reading and to look for other categories they might want to add to their semantic maps.

- When the class is finished reading the selection, return to the master semantic map on the board (or overhead/IWB). Discuss the concepts included in the reading. Add new concepts learned during reading to the semantic map.

- Ask students whether they discovered any other categories, or groups of things with common characteristics, in the reading. If needed, think aloud for the class.

- Have students work with partners to fill in examples under each new category. When students are finished, ask for responses and discuss.

\section{Independent Practice}

- Before reading a passage or selection, preview the text for challenging words students will use and see often (see procedure at the beginning of this lesson).

- Tell students the topic of the reading passage or selection and lead students to brainstorm a list of words related to the topic. Discuss background knowledge of the topic and help students make connections between what they already know and what they will learn while reading.

- Working in small groups or partners, ask students to create a semantic map by categorising the brainstormed list of words. This includes generating logical category titles and placing words in appropriate categories.

- As students read have them add new vocabulary words to their maps. Discuss with students the meaning of the new words and where they fit on the map.

- After students read the passage have them add any other vocabulary words to the map. Return to whole group and discuss students' semantic maps. Discuss with the students how the semantic map might be expanded or reorganized to reflect new information they learned

\section{Generalization}

Identify situations in Key Learning Areas where students could use semantic maps to assist their understanding of the vocabulary in a topic/concept. 